\title{
Role of prevention and screening in epithelial ovarian cancer
}

\author{
Peddireddi Reddi Rani ${ }^{1 *}$, Kanipakapatnam Sathyanarayana Reddy ${ }^{2}$
}

\begin{abstract}
${ }^{1}$ Department of Obstetrics \& Gynaecology, ${ }^{2}$ Department of Radiation Oncology, Mahatma Gandhi Medical College \& Research Institute, Pilliarkuppam, Puducherry 607 402, India
\end{abstract}

Received: 10 June 2015

Accepted: 09 July 2015

\author{
*Correspondence: \\ Dr. Kanipakapatnam Sathyanarayana Reddy, \\ E-mail: satyare@ hotmail.com
}

Copyright: ( $)$ the author(s), publisher and licensee Medip Academy. This is an open-access article distributed under the terms of the Creative Commons Attribution Non-Commercial License, which permits unrestricted non-commercial use, distribution, and reproduction in any medium, provided the original work is properly cited.

\begin{abstract}
Epithelial ovarian carcinoma is a disease with poor prognosis and high mortality among gynaecological cancers due to inaccessibility of ovary for inspection or sampling and lack of proper screening methods. Strategies to detect early ovarian cancer include estimation of serum CA-125 and transvaginal ultrasound (TVS) for morphological index. Studies have shown that screening of asymptomatic average risk post-menopausal women did not show any benefit and are associated with false positive results which may lead to unnecessary surgery and resultant morbidity. The risks outweigh benefits.

Present recommendation is to screen high risk women especially hereditary cancers and offer risk reducing surgery when needed. Prophylactic salpingectomy/oophorectomy may offer the opportunity to prevent ovarian cancer. More trials and more research in newer biomarkers are needed.
\end{abstract}

Keywords: Screening, Transvaginal ultrasound, CA-125, Risk reducing surgery

\section{INTRODUCTION}

Of all gynaecological malignancies ovarian cancer carries the worst prognosis and it is estimated to be the ninth most common cancer and fifth most common cancer related mortality. Most of them are diagnosed in advanced stages of III and IV with a five year survival rate of less than $28 \%$. Only $15 \%$ of ovarian cancers are diagnosed in early stage with a five year survival rate of 94\%. ${ }^{1}$ This suggests that early detection will improve prognosis. Early diagnosis is often difficult due to lack of specific symptoms and also ovaries are inaccessible for direct inspection and palpation. Despite the significant disease burden ovarian cancer is relatively rare in general population with an estimated age adjusted incidence of 13 per 100,000 women. ${ }^{2}$ The age standardized incidence rate (ASR) varies widely; as low as 0.06 per 100,000 in China to as high as 16.3 in Switzerland. ${ }^{3}$ In India during the period 2004-5 proportion of ovarian cancer varied from $1.7 \%$ to $8.7 \%$ of all cancers affecting women as reported by various urban and rural population based cancer registries operating under the network of National Cancer Registry Programme of the Indian Council of Medical Research. ${ }^{4}$ Screening tests lack specificity and there is no single effective screening test for ovarian cancer. Main strategies for screening include biochemical markers and transvaginal ultrasound (TVS).

\section{Screening}

\section{Low risk women}

Use of tumour marker CA-125 and TVS has been evaluated for screening asymptomatic low risk women. These proved to be ineffective because of low prevalence of epithelial cancer which is reported to be approximately 1 case for 2,500 women per year. It is estimated that a test with $100 \%$ sensitivity and $99 \%$ specificity would have a positive predictive value of only $4.8 \%$ which means 20 out of 21 women undergoing surgery for suspected ovarian cancer will not have the disease. ${ }^{5}$ 


\section{High risk women}

The definite risk factor known to increase the risk of ovarian cancer include an identified BRCA gene mutation and a family history of cancer which is suggestive of ovarian cancer syndrome. Women with these conditions should be referred for genetic testing for proper assessment of the risk of developing ovarian cancer. Women with BRCA-1 mutation have a life time risk of $63 \%$ for developing ovarian cancer before the age of 70 years and breast cancer risk is $85 \%$. Risk of developing ovarian and breast cancer are $27 \%$ and $84 \%$ respectively among women who show BRCA-2 mutations before the age of 70 years. ${ }^{6}$

Women with Lynch syndrome/hereditary non-polyposis colorectal cancer(HNPCC) caused by DNA mismatch repair genes carry the risk of developing endometrial cancer in $42-60 \%$, ovarian cancer in $9-12 \%$ by the age of 70 years and also have $40-60 \%$ life time risk of developing colorectal cancer. ${ }^{7}$

The strongest known risk factor is a family history of the disease which is present in about $10-15 \%$ of women with ovarian cancer. Women with a single family member affected by epithelial ovarian cancer have a risk of $4-5 \%$, while with two affected family members the risk is $7 \%$. Women with hereditary ovarian cancer syndrome defined as having at least two first degree relatives with epithelial ovarian cancer have a life time probability as high as 13$55 \%$ to develop epithelial ovarian cancer. ${ }^{8}$

\section{Other risk factors}

1. Age- Incidence increases with age; median age at diagnosis is 63 .

2. Obesity

3. Hormone replacement therapy (HRT)

4. Early menarche and late menopause

5. Endometriosis

6. Smoking

7. Association between ovulation induction and ovarian carcinoma Infertility alone is an independent risk factor. Nulliparous women have a higher risk of ovarian cancer irrespective of usage of fertility drugs. A 2013 Cochrane review concluded that there may be an increased risk of borderline ovarian tumours in sub-fertile women but no convincing evidence of increase in the risk of invasive epithelial ovarian cancer with fertility drug usage. ${ }^{9}$

Table 1: Summary of risk factors and protective factors by strength of evidence. ${ }^{10}$

\begin{tabular}{|c|c|c|c|c|}
\hline & $\begin{array}{l}\text { Established } \\
\text { risk factors }\end{array}$ & $\begin{array}{l}\text { Possible } \\
\text { risk factors }\end{array}$ & $\begin{array}{l}\text { Suspected } \\
\text { risk factors }\end{array}$ & $\begin{array}{l}\text { Protective } \\
\text { factors }\end{array}$ \\
\hline 1 & $\begin{array}{l}\text { Family } \\
\text { history and } \\
\text { BRCA } \\
\text { mutation } \\
\text { status }\end{array}$ & $\begin{array}{l}\text { Early age at } \\
\text { menarche }\end{array}$ & HRT & Lactation \\
\hline
\end{tabular}

\begin{tabular}{|lllll|}
\hline 2. Age & $\begin{array}{l}\text { Late age at } \\
\text { menopause }\end{array}$ & Obesity & Tubal ligation \\
\hline 3. Nulliparity & Infertility & $\begin{array}{l}\text { Sedentary } \\
\text { life style }\end{array}$ & Hysterectomy \\
\hline 4. & & $\begin{array}{l}\text { Low } \\
\text { vegetable } \\
\text { intake }\end{array}$ & $\begin{array}{l}\text { Oral contra- } \\
\text { ceptive pill use }\end{array}$ \\
\hline 5. & & $\begin{array}{l}\text { Cigarette } \\
\text { smoking }\end{array}$ & Oophorectomy \\
\hline
\end{tabular}

\section{Screening methods}

ACOG recommends that the best way to detect ovarian cancer is for both the patient and her clinician to have a high index of suspicion of the diagnosis in symptomatic women. ${ }^{11}$ But there are no tests that could reliably detect ovarian cancer in its earliest and most curable stage and so educating women and practitioners about symptoms and prompt initiating work up helps in timely diagnosis and treatment.

Symptoms and signs are usually present 3-6 months at least before diagnosis, these include increased distension or bloating, abdominal or pelvic pain, feeling full quickly or difficulty in eating etc. These symptoms and signs should be evaluated with suspicion of ovarian cancer, with pelvic examination, TVS and CA-125. Though a thorough bimanual pelvic examination is cost effective, it is not cost sensitive to detect ovarian cancer in asymptomatic women.

\section{Tumour markers}

CA-125 is the most extensively studied tumour marker in ovarian carcinoma. $\mathrm{Ca}-125$ is a glycoprotein produced by majority of epithelial ovarian cancer (EOC). It is elevated in $61-95 \%$ of symptomatic patients with EOC and in 29$75 \%$ of those with stage I disease. ${ }^{12}$ Normal value is 30 $35 \mathrm{U} / \mathrm{ml}$, it is influenced by menopausal status. In premenopausal women the sensitivity is decreased. It also can be elevated in other cancers like endometrial, breast, lung, lymphoma, colorectal cancer etc. It is also elevated in certain benign conditions like endometriosis, uterine leiomyoma, pregnancy, PID etc. It is not specific for ovarian cancer. In malignancy serial measurements show increase in value. Screening using a single CA-125 measurement is not specific with low sensitivity. Serial measurements combined with TVS improves sensitivity and specificity.

\section{Trans vaginal sonography}

It has been found to be safe and effective means visualizing ovaries. The earlier studies mainly focused on ovarian volume, normal premenopausal ovarian volume established to be $>20 \mathrm{ml}$ and for post menopausal women the cut off value is $8-10 \mathrm{ml}$. Risk Malignancy Index (RMI) is the most widely used index to diagnose ovarian cancer in suspected cases. It combines three pre-surgical features: serum CA-125, menopausal status (M) and Ultrasound score (U). 


\section{RMI: U x M x CA-125}

$\mathrm{U}$ : One point for each of these morphological criteriamultilocular cysts, solid areas, bilateral lesion, metastases, ascites

M: Menopausal status is scored as 1 for premenopausal and 3 for postmenopausal status.

RMI score of 200 indicates high degree of suspicion of ovarian malignancy, sensitivity of $78 \%$ and specificity of $87 \% .{ }^{13}$

Table 2: Morphological criteria of USG from TOTA group as benign and malignant has a sensitivity of $95 \%$ and specificity of $91 \% . .^{14}$

\begin{tabular}{|ll|}
\hline Benign Features & Malignant features \\
\hline Unilocular cysts & Irregular solid tumour \\
\hline $\begin{array}{l}\text { Presence of solid } \\
\text { component is }<7 \mathrm{~mm}\end{array}$ & $\begin{array}{l}\text { Atleast four papillary } \\
\text { structures }\end{array}$ \\
\hline $\begin{array}{l}\text { Presence of acoustic } \\
\text { shadowing }\end{array}$ & \\
\hline $\begin{array}{l}\text { Smooth multiloculated } \\
\text { tumour with largest } \\
\text { tumour size }<100 \mathrm{~mm}\end{array}$ & $\begin{array}{l}\text { Irregular multilocular } \\
\text { solid tumour with largest } \\
\text { diameter } \geq 100 \mathrm{~mm}\end{array}$ \\
\hline No blood flow & Very strong blood flow \\
\hline
\end{tabular}

The routine use of CT/MRI for assessment of ovarian masses does not improve sensitivity and specificity obtained by TVS in the detection of ovarian malignancies. What is needed is a multimodal screening using CA-125 and ultrasound. Patient should be referred to a specialist if four or more of the following indicators are present. ${ }^{15}$

1. Premenopausal $(<50$ Years $)$
A. CA- $125>200 \mathrm{U} / \mathrm{ml}$
B. Ascites
C. Evidence of abdominal/distant metastases by scan or imaging studies.
D. Family history of breast or ovarian carcinoma (first degree relatives)

2. Post menopausal women $(\geq 50$ years $)$
A. Elevated CA-125>35 U/ml
B. Ascites
C. Nodular or fixed pelvic mass
D. Abdominal or distant metastases
E. Family history of breast or ovarian carcinoma (first degree relatives)

\section{Biomarkers in ovarian carcinoma}

Apart from CA-125, other biomarkers which may lead to early detection ovarian cancer HE-4 transthyretin, CA15-3 and CA 72-4 were evaluated using specimens assembled from multiple cohort randomized trials including PLCO trial. Phase II and phase III biomarker studies concluded that CA-125 remained the "single best biomarker" for ovarian cancer. ${ }^{16}$
Moore et $\mathrm{al}^{17}$ evaluated proteomic biomarkers which include apolipoprotein a-1, truncated transthyretin, transferrin, hepcidin, beta-2 microglobulin, connective tissue activating protein III and interalpha-trypsin inhibitor heavy chain in addition to CA-125 and concluded that addition of these seven proteins did not improve sensitivity beyond the use of CA-125 levels alone.

Yushan Cheng et $\mathrm{a}^{18}$ found retinol binding protein-4 (RBP-4) found to be a potential biomarker in screening for ovarian cancer. They found concentrations of this biomarker was much higher (mean $89.13 \pm 1.67 \mathrm{ng} / \mathrm{ml}$ ) in ovarian cancer patients compared to healthy women (mean $10.85 \pm 2.38 \mathrm{ng} / \mathrm{ml}$ ).

Challenges in developing screening strategies in ovarian cancer:

1. No definite preinvasive or precursor lesion

2. Ovary is not accessible like cervix for direct inspection and sampling

3. Risk of false positives in ovarian cancer screening is a setback.

There is low prevalence of ovarian carcinoma. Incidence in women > 50 years it is 40 per 100,000 women. One needs to screen 2500 women to detect a single case of ovarian cancer and also requires invasive procedures like laparoscopy/ laparotomy. ${ }^{19}$ Current screening tests cannot detect ovarian cancer early enough to alter the natural history of the disease. Low prevalence affects sensitivity and specificity.

The ACOG recommends against screening for ovarian cancer in general population. The U.S. Preventive services task force gives ovarian cancer screening a grade 'D' recommendation, which indicates that women are harmed with false positive results than helped by early detection and hence it should be eliminated from a periodic health examination. It gives a grade ' $\mathrm{B}$ ' recommendation for genetic counseling and testing of women with a pedigree consistent with a familial mutation that would increase the risk of ovary and other malignancies offering risk-reducing surgery dramatically lowers the risk of developing ovarian, fallopian tube or primary peritoneal cancer. ${ }^{20}$

\section{Harms of screening}

PLCO trial (Prostate, lung, colorectal and ovarian cancer trial) provides the most reliable data to date on ovarian screening related harms. ${ }^{21}$ This is a large prospective randomized screening trial; 78,232 women in age group of 55-74 years were randomly assigned to screening who underwent annual TVS for 4 years and annual CA-125 for 6 years. Controls were women who were assigned for routine care. Median follow up of participants was 12.4 years. Ovarian cancer was diagnosed in 212 women in the screened group and 176 in the control group. There were 118 deaths caused by ovarian cancer in screened 
group compared to 100 deaths among controls. Screening with annual TVS and CA-125 did not reduce the ovarian cancer mortality. Of the 3285 women with false positive result, 1080 underwent surgery and 163 (15\%) experienced at least one serious complication. This confirms that ovarian cancer screening in asymptomatic low risk women can lead to unintended harm. Major complications with diagnostic procedures among women diagnosed with ovarian cancer included bowel injury, infections, blood loss and cardio vascular events.

US Preventive services task force (USPSTF) ${ }^{22}$ concluded that screening asymptomatic women for ovarian cancer via USG, serum tumour markers was not recommended. There was fair evidence that screening by CA-125, and TVS resulted in detection of ovarian cancer at an earlier stage but there was also evidence that impact on survival was small and that the potential harms of invasive testing might outweigh potential benefits. It did not decrease the cancer specific or overall mortality compared with usual care. There were potential harms associated with false positive screening test results, unnecessary surgeries and associated complications. There is no evidence for routine screening in average risk asymptomatic women.

UK Collaborative trial of ovarian cancer screening

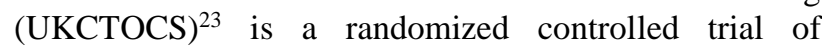
202,638 post menopausal women aged 50-74 years who were randomized into three groups. First group had annual screening with CA-125 testing, if abnormal followed up with TVS (multi modal screening group MMS), the second group had screening with TVS annually(USS) and the third group did not have any screening. Abnormal screening test results were repeated; if abnormality persisted they were evaluated and treated. The number of cancer cases detected were similar; 42 in MMS group and 45 in USS group. More borderline tumours were detected in USS group 20 vs 8 in MMS group. There was significant difference in specificity but not in sensitivity between the MMS and USS group for both ovarian and tubal carcinoma. Overall $48.3 \%$ of invasive cancer cases were early stage I or II with no significant stage distribution difference the two groups. Primary study results on mortality and other parameters from UKCTOS are awaited by late 2015. This may provide information on the complicated screening algorithms. The high proportion of early stage tumours detected is encouraging.

\section{Preventive or risk reducing factors}

Risk reducing surgery for women at high risk of developing epithelial ovarian cancer

The life time risk of ovarian cancer in the general population is $1.4 \%$ to $1.7 \%$ and in women

With hereditary ovarian cancer syndromes the risk is as high as $25-60 \%$. It is important to identify the cancers caused by an inherited predisposition in the light of prognostic implications for individuals and their families. Genetic risk assessment in these patients helps to provide individualized evaluation of the likelihood of having one of these gynaecologic cancers and also to provide tailored screening and preventing strategies such as surveillance, chemoprevention and prophylactic surgery which may reduce morbidity and mortality. Strategies that improve the outcome are breast cancer screening by MRI, colorectal cancer screening by colonoscopy, annual screening for ovarian cancer by CA-125 and TVS and offering prophylactic surgery. These procedures reduce the risk of ovarian cancer by $96 \%$ and breast cancer by $53 \%$ in women with BRCA-1 and BRCA-2 mutation. ${ }^{24}$

Table 3: Guidelines for the management of women at increased risk of epithelial ovarian cancer. ${ }^{25}$

\begin{tabular}{|c|c|}
\hline Risk of Ovarian Cancer & Suggested Management \\
\hline \multicolumn{2}{|l|}{ 1. Increased risk } \\
\hline $\begin{array}{l}\text { Positive family history } \\
\text { Single member affected } \\
\text { Not suggestive of a } \\
\text { hereditary cancer syndrome } \\
\text { Risk of ovarian cancer } 4-5 \% \\
\text { (Risk in general population } \\
1.7 \% \text { ) }\end{array}$ & $\begin{array}{l}\text { Can consider risk reducing } \\
\text { bilateral salpingo } \\
\text { oophorectomy (BSO) based } \\
\text { on individual considerations }\end{array}$ \\
\hline \multicolumn{2}{|l|}{ 2. High risk } \\
\hline $\begin{array}{l}\text { Family history suggestive of } \\
\text { Hereditary cancer syndrome } \\
\text { Risk of ovarian cancer-13- } \\
50 \%\end{array}$ & $\begin{array}{l}\text { No evidence to support } \\
\text { screening in this group } \\
\text { Offer risk reducing surgery } \\
\text { Screening to those who } \\
\text { decline surgery }\end{array}$ \\
\hline $\begin{array}{l}\text { BRCA- } 1 \text { mutation has a life } \\
\text { time risk of ovarian cancer } \\
35-46 \%\end{array}$ & $\begin{array}{l}\text { Offer risk reducing surgery } \\
\text { (BSO) after the age of } \\
35 y e a r s \text { when child bearing } \\
\text { is complete. }\end{array}$ \\
\hline $\begin{array}{l}\text { BRCA- } 2 \text { mutation has a life } \\
\text { time risk of ovarian cancer } \\
13-23 \%\end{array}$ & $\begin{array}{l}\text { Offer risk reducing surgery } \\
\text { (BSO) after the age of } \\
35 y e a r s \text { when child bearing } \\
\text { is complete. } \\
\text { May be delayed until the } \\
\text { age of } 45 \text { years because of } \\
\text { later age of onset but may } \\
\text { lose the benefit of reduction } \\
\text { in breast cancer risk }\end{array}$ \\
\hline $\begin{array}{l}\text { HNPCC or Lynch syndrome } \\
\text { has life time risk of ovarian } \\
\text { cancer } \\
3-14 \%\end{array}$ & $\begin{array}{l}\text { Offer risk reducing surgery } \\
\text { (BSO) with concomitant } \\
\text { hysterectomy after child } \\
\text { bearing is complete because } \\
\text { of the risk of developing } \\
\text { ovarian and endometrial } \\
\text { cancer. }\end{array}$ \\
\hline
\end{tabular}

\section{Role of salpingectomy}

The site of origin of pelvic (ovarian, fallopian tube, peritoneal) high grade serous carcinoma has been the subject of debate. One of the theories proposed involved malignant transformation of distal fallopian tube mucosa through P-53 signatory and the development of serous tubal intra epithelial carcinoma (STIC). These STIC lesions may invade locally into the underlying tubal wall, exfoliate on to the surface of the ovary or peritoneal 
cavity or a combination of these. This exfoliation into the peritoneal cavity could explain the clinical finding of widespread high grade serous ovarian carcinoma in the absence of significant volume of invasive disease in the fallopian tube and ovary. ${ }^{26}$

In high risk women with an identified BRCA mutation, $\mathrm{BSO}$ offers the greatest risk reduction of ovarian cancer and significant reduction of breast cancer. Bilateral salpingectomy with delayed oophorectomy may be a cost effective strategy that could overcome the quality of life issues associated with bilateral oophorectomy in premenopausal women. ${ }^{25}$

A 2014 RCOG scientific impact factor opines that women who are not at a high risk of BRCA mutation and have completed their families should be carefully considered for prophylactic removal of fallopian tubes with conservation of ovaries at the time of gynaecological or other intraperitoneal surgery. ${ }^{27}$

\section{Other protective factors}

Include multiparity, breast feeding, tubal ligation, hysterectomy and oral contraceptive pills (OCP) usage. OCP use is associated with decreased risk of ovarian cancer and protective effect persists for a longer time after stopping its use.

\section{CONCLUSION}

Majority of epithelial ovarian cancers are detected in late stages with poor survival rates. Based on various trials at present there is no role for screening asymptomatic average risk women. High risk women require multimodality screening and risk reducing surgery. Results of UKCTOCS are awaited which is the largest trial, though initial results showed increased detection of early ovarian cancer. Further research is also needed in biomarkers.

Funding: No funding sources

Conflict of interest: None declared

Ethical approval: Not required

\section{REFERENCES}

1. American cancer society, Cancer facts and figures 2011. Atlanta, GA; American Cancer Society:2011

2. National Cancer Institute. SEER stat fact sheets Ovary, Bethesda, MD; National Cancer Institute:2011.

3. Parkin DM, Whelan SL, Ferlay J et al.(eds). Cancer incidence in Five Continents, Vol VIII, International Agency for Research in Cancer, Lyon, France, IARC Publication No:155, 2002.

4. National Cancer Registry Programme, Indian Council of Medical Research, Two year report of population based Cancer Registries, 2004-5, Incidence and distribution of Cancer, Bangalore, India, 2008.
5. Daniilidas A, Karagiannis V. Epithelial ovarian cancer risk factors, screening and role of Prophylactic oophorectomy. Hippokratia.s 2007;11:63-6.

6. Easton DF, Ford D, Bishop DT. Breast and ovarian cancer incidence in BRCA mutation carriers, Breast cancer linkage consortium. Am J Hum Genet. 1995;56:265-71.

7. Johnathan M, Lancaster C, Bethan P, Noah D et al. Statement on risk assessment for inherited gynaecologic cancer predisposition. Gynecologic Oncology. 2007; 107:159-62.

8. Chen S, Parmigiani G. Meta-analysis of BRCA-1 and BRCS-2 penetrance. J Clin Oncol. 2007;25:1329-33.

9. Rizzuto I, Behrens RF, Smith LA. Risk of ovarian cancer in women treated with ovarian stimulating drugs for infertility. Cochrane Data Base Syst Rev 2013;8:CD008215.

10. Permuth-wey J, Sellars TA. Epidemiology of ovarian cancer-Methods of molecular biology. Cancer epidemiology. 2009;472:413-7.

11. The American College of Obstetricians and Gynecologists Committee Opinion, The Role of the Obstetrician-Gynecologist in the early detection of Epithelial Ovarian Cancer. Obstet Gynecol 2011;117:742-6.

12. Carlson KJ, Skates SJ, Singer DE. Screening for ovarian cancer. Ann Intern Med 1994; 121: 124-32.

13. Geomini P, Kruit Wagen R, Bremer GI et al. The accuracy of risk factors in predicting ovarian malignancy, A systematic review. Obstet Gynecol 2009; 113:384-94.

14. Timmerman D, Valentin L, Bourne TH et al. International Ovarian Tumor analysis (TOTA) group terms, definitions and measurements to describe the sonographic features of adnexal tumors, A consensus opinion from International ovarian tumor analysis group. Ultrasound Obstet \& Gynecol. 2000;16:500-5.

15. ACOG practical bulletin No.83, Management of adnexal masses. Obstet Gynecol. 2007;110:201-14.

16. Cramer DW, Bast RC Jr, Berg CD et al. Ovarian cancer biomarker performance In prostate, lung, colorectal, ovarian cancer screening trial specmens. Cancer Prev.Res(Phila). 2011;4(3):365-74.

17. Moore LE, Pfeiffer RM, Zhang $Z$ et al. Protemic biomarkers in combination with CA-125 for detection of epithelial ovarian cancer using pre-diagnostic serum samples from prostate, lung, colorectal, ovarian (PLCO) cancer screening trial. Cancer 2012;118(1):91-100.

18. Yushen Cheng, Chongdong Liv, Naweizhang et al.Proteomics analysis for finding serum markers of ovarian cancer. Biomed Research International. 2014, Article ID: 179040

19. Bast RC Jr, Brewer M, Zou C, Hernandez MA et al. Preventive and early detection of ovarian carcinoma: mission Impossible? Recent Results Cancer Res. 2007;174:91-100. 
20. US Preventive services Task force, Genetic risk assessment and BRCA mutation testing for breast and ovarian cancer susceptibility. Ann Intern Med 2005;143:355-61.

21. Buys SS, Partridge E, Black A et al. Effect of screening on ovarian cancer mortality: The prostate, lung, colorectal and ovarian (PLCO) cancer screening, Randomised controlled trial. JAMA. 2011;305:2295-303.

22. Danforth KN, Theresa M, Whitelock EP. Addendum to screening for ovarian cancer: Evidence update for the US Preventive services task force reaffirmation recommendation statement. AHRQ Publication No:12-05165-EF4 April 2012.

23. Menon V, Gentry-Maharaj A, Hallet et al. Sensitivity ansd specificity of multimodal and ultrasound screening for ovarian cancer and stage distribution of detected cancers-Results of the prevalence of the UK collaborative trial of Ovarian cancer screening (UKCTOCS) Lancet Oncol. 2009;10(4):327-40.
24. Rebbeck TR, Lynch HT, Neuhausen SL et al. Prophylactic oophorectomy in BRCA-1 or BRCA-2 mutations. N Eng J Med. 2002;346:1616-22.

25. EveMaria GG, Thomas Anthony W. Risk reducing surgey for women at high risk of epithelial ovarian cancer. The Obstetrician and Gynaecologist. 2014;16:185-91.

26. Carlson JW, Miran A, Jarboe EA et al. Serous tubal intraepithelial carcinoma: its potential role in primary peritoneal serous carcinoma and serous cancer prevention. J ClinOncol 2008; 26:4160-5.

27. Kwon JS, Tinker A, Pansegrau G et al. Prophylactic salpingectomy and delayed oophorectomy as an alternative for BRCA mutation carriers. Obstet Gynecol 2013;121:14-24.

28. RCOG- The distal fallopian tube as the origin of non-uterine pelvic high grade serous carcinomas. Scientific impact paper N0:44, Nov 2014 :2-8.

Cite this article as: Rani PR, Reddy KS. Role of prevention and screening in epithelial ovarian cancer. Int J Reprod Contracept Obstet Gynecol 2015;4:9416. 